\title{
Educação para idosos em tempo de pandemia no Núcleo de Estudos da Terceira Idade: relato de experiência
}

\author{
Education for elderly people in pandemic time in The Núcleo de \\ Estudos da Terceira Idade: experience report
}

\section{Educación para adultos mayores en tiempo pandemia en el Núcleo de Estudos da Terceira Idade: informe de experiencia}

Michele Medeiros'

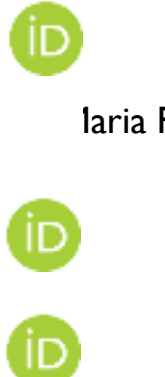
https://orcid.org/0000-000I-7798-3963 laria Fernanda Baeta Neves Alonso da Costa² https://orcid.org/0000-0002-2763-8050 Guilherme Henrique Koerich ${ }^{3}$ https://orcid.org/0000-0003-I585-6998

Resumo: A pandemia de COVID-19 trouxe a necessidade de reformulações nos processos educacionais, em especial, às pessoas idosas. $O$ distanciamento social e a educação mediada pelas tecnologias digitais se fizeram necessárias. Este relato apresenta a estratégia de manutenção do vínculo com os estudantes idosos do Núcleo de Estudos da Terceira Idade (NETI), com a proposição do "Programa Quarentena no NETI". O desenvolvimento do projeto se dá por postagens semanais, de diferentes materiais e conteúdos nos grupos de

\footnotetext{
1 Mestre em Gestão do Cuidado em Enfermagem pela UFSC- Universidade Federal de Santa Catarina.Enfermeira no Núcleo de Estudos da Terceira Idade da UFSC- Universidade Federal de Santa Catarina. E-mail: mtmedeiro@gmail.com.

2 Doutora em Ciências da Saúde pela EEUSP- Escola de Enfermagem da Universidade de São Paulo. Coordenadora do Núcleo de Estudos da Terceira Idade e docente da Universidade Federal de Santa Catarina. E-mail: mafebaeta@gmail.com.

${ }^{3}$ Especialista em Educação Física Escolar e Mestrando em Educação Física. Professor. ASSOBES ENSINO SUPERIOR. eeugeniolsj@gmail.com
}

Olhar de professor, Ponta Grossa, v. 24, p. I-9, e-I58I4.028, 2021.

Disponível em <https://revistas2.uepg.br/index.php/olhardeprofessor> 
WhatsApp das atividades ofertadas. O Programa foi avaliado pelos estudantes idosos via questionário on-line, dos quais $96,7 \%$ demonstraram muita satisfação e satisfação com os conteúdos. Os materiais abordam diferentes conteúdos, temas e formatos, sendo que os vídeos são os prediletos dos estudantes idosos. Concluise que o programa demonstra ser uma experiência exitosa, uma vez que, tem proporcionado vínculo com os estudantes e o compartilhamento de informações durante a pandemia de COVID-19.

Palavras-chave: Educação. COVID-19. Idosos.

\begin{abstract}
The COVID-19 pandemic raised the need for reformulations in educational processes, especially for the elderly. Social distance and education through digital technologies became mandatory. This report presents the strategy of maintaining the link with the elderly students of the Núcleo de Estudos da Terceira Idade (NETI) with the proposal of the "Quarantine Program at NETI". The program consists of weekly messages of several subjects and topics in WhatsApp groups of the activities offered. The program was evaluated by elderly students through an on-line questionnaire, which $96.7 \%$ showed great satisfaction and satisfaction with the content. The subjects and topics address different contents, themes and formats, and the videos are the favorite option for the elderly students. In conclusion, the program has been a successful experience since it has provided links with the elderly students and the sharing of information during the COVID-19 pandemic.
\end{abstract}

Keywords: Education. COVID-19. Elderly.

Resumen: La pandemia de COVID-19 trajo la necesidad de reformulaciones en los procesos educativos, especialmente para los adultos mayores. La distancia social y la educación mediada por las tecnologías digitales son necesarias. Este informe presenta la estrategia de mantener el vínculo con los estudiantes mayores del Núcleo de Estudos da Terceira Idade (NETI), con la propuesta del "Programa de Cuarentena en NETI". EI desarrollo del proyecto ocurre a través de publicaciones semanales, de diferentes materiales y contenidos en los grupos de WhatsApp de las actividades ofrecidas. El programa fue evaluado por estudiantes mayores a través de un cuestionario em linea, de los cuales, $96.7 \%$ mostraron gran satisfacción y satisfacción con el contenido. Los materiales abordan diferentes contenidos, temas y formatos, y los videos son los favoritos de los estudiantes mayores. Se concluye que el programa se ha presentado como una experiencia exitosa, ya que han proporcionado enlace con los estudiantes y el intercambio de información durante la pandemia COVID-I9.

Palabras-clave: Educación. COVID-19. Adultos mayores.

\title{
Introdução
}

mundo inteiro, com maior intensidade nos primeiros dias deste ano, tem estado atento às notícias que vieram da China sobre o aumento do número de casos de um quadro atípico de síndrome respiratória por um novo vírus. Na China, assim como em outros países, passaram a ativar seus centros de emergência em Saúde Pública no combate à contaminação do agente etiológico identificado (SARS-COV2), que provoca a denominada COVID-19. Desde então, a COVID-19 se espalhou rapidamente por todos os continentes e, no início de março, a Organização Mundial da Saúde decretou que estávamos vivendo uma pandemia (LIMA et al., 2020).

Especificamente no Brasil, em 03 de fevereiro de 2020, o Ministério da Saúde declarou a emergência em Saúde Pública de Importância Nacional (ESPIN) e, em seguida, sancionou a Lei $\mathrm{n}$. 13.979, de 06 de fevereiro de 2020, que dispõe sobre as medidas para enfrentamento da emergência de importância de caráter nacional e internacional, decorrente da COVID-I9 (BRASIL, 2020a). No mês seguinte, o Brasil declarou a situação de transmissão comunitária em todo o território nacional por meio da Portaria $n^{\circ} 454$ de 20 de março de 2020 e, com isso, as medidas de quarentena, 
isolamento e distanciamento social foram se tornando mais consistentes (BRASIL, 2020b; LIMA et al., 2020).

Medidas de prevenção e proteção vêm se preconizando de forma eficaz na redução das várias formas de contágio em todos os locais onde há presença de pessoas idosas. Seja no contexto dos seus domicílios, assistidos por cuidadores e familiares, sob distanciamento social, assim como para os residentes em Instituições de Longa Permanência para Idosos (ILPIs), contribuindo com a diminuição da mortalidade na faixa etária de 60 anos e mais (LIMA et al., 2020).

A pandemia pelo COVID-I9 tem causado reformulações aos conceitos de vida, trabalho e educação no mundo. Seu alto potencial de transmissão, a inexistência até o momento de vacinas e/ou medicamentos que curem a infecção, o risco de desenvolvimento da forma grave da doença com o avançar da idade, fizeram do distanciamento social uma medida-chave adotada em muitos países como forma de reduzir a transmissão em massa do vírus.

Com esse distanciamento social, as atividades educativas presenciais no Brasil foram suspensas, fomentando aos educadores a necessidade de pensar e propor estratégias de ensino não presenciais para seus estudantes. Na Universidade Federal de Santa Catarina, o distanciamento social e a consequente suspensão das atividades de ensino presencial e à distância, tiveram início no dia 18 de março de 2020. Já o Núcleo de Estudos da Terceira Idade da Pró-Reitoria de Extensão da Universidade Federal de Santa Catarina (NETI/PROEX/UFSC), tendo em vista que seus estudantes idosos pertencem ao grupo de risco, devido às condições de vulnerabilidade social e comorbidades, tiveram suas atividades suspensas no dia 16 de março do mesmo ano.

O NETI é considerado uma Universidade Aberta da Terceira Idade (UNATI). As UNATIs têm por objetivo propiciar um ambiente de aprendizagem e diálogo, com vistas ao exercício da cidadania, ocupação do tempo livre, e o estabelecimento de vínculos sociais (CACHIONI; ORDENEZ, 20I7). À luz disto, o NETI oferta atividades socioeducativas para idosos, com 50 anos e mais de idade, as quais têm um caráter de ensino não formal, com oferta semestral e incluem oficinas, seminários, palestras e workshops. Em sua maioria, estas atividades acontecem com um encontro semanal, com duração de 2 horas, totalizando 15 encontros por semestre. $O$ acesso a estas ações socioeducativas é regido e regulamentado por edital próprio. $\mathrm{O}$ edital para ingresso no primeiro semestre de 2020 foi publicado em 30 de dezembro de 2019 e as etapas de inscrição foram realizadas em fevereiro de 2020. Anterior à suspensão das atividades.

O primeiro semestre de 2020 teria início em 16 de março, para os inscritos no NETI. Todavia, em Nota Oficial do Magnífico Reitor foram suspensas as atividades. Dado este cenário de suspensão, tornou-se imprescindível pensar em proteger o público idoso do Núcleo e estabelecer restrições para que este permanecesse em condições de severo distanciamento social. Assim, a

Olhar de professor, Ponta Grossa, v. 24, p. I-9, e-I58I4.028, 2021.

Disponível em <https://revistas2.uepg.br/index.php/olhardeprofessor> 
Educação para idosos em tempo de pandemia no Núcleo de Estudos da Terceira Idade: relato de experiência equipe do NETI concebeu, em 30 de março, o projeto de extensão intitulado "Programa Quarentena no NETI".

O projeto visa manter o vínculo com os estudantes idosos do NETI, durante o período de distanciamento social, e promover a saúde destes, por meio de ações educativas. As ações do projeto consistem no envio de materiais educativos relacionados a diferentes temas e à pandemia pelo novo Coronavírus, bem como de conteúdos de entretenimento, estimulação da memória e mensagens de conforto. O conteúdo é enviado periodicamente duas vezes na semana, por meio da ferramenta WhatsApp, a esses alunos. Espera-se que, com o Programa, sejam disseminadas informações sobre a pandemia do COVID-19, haja a manutenção do vínculo dos estudantes com os professores e a participação dos estudantes do NETI.

Esse artigo trata do relato da experiência acerca da implementação do Programa Quarentena no NETI, trazendo um compilado de suas postagens, os assuntos abordados e as ferramentas didáticas escolhidas para apresentar os conteúdos. Aborda também a primeira avaliação sobre os dez episódios iniciais do Programa, realizada com os estudantes idosos do NETI. A relevância do tema está em tornar visíveis ações de cunho informativo e educativo, refletidas e destinadas a esses estudantes idosos e, em fornecer subsídios para pensar e repensar a interação com/do idoso no contexto da pandemia pela COVID-19.

\section{Metodologia}

No NETI são desenvolvidas atividades de educação não formal, de cunho socioeducativo, com vistas ao compartilhamento de conhecimentos e experiências, em espaços e ações coletivas, sem a preocupação de certificar o estudante. Suas atividades se fundamentam na Política Nacional do Idoso (Lei n. 8.842/1994) e no Estatuto do Idoso (Lei n. 10.74I/2003), que estabelece à pessoa idosa o direito à educação, metodologias e material didático aos programas educacionais a ela destinados (BRASIL, 1994; BRASIL, 2003).

Neste primeiro semestre de 2020 foram oferecidas no NETI 29 atividades socioeducativas, as quais contaram com 446 idosos inscritos em uma ou duas atividades ofertadas. Quanto ao perfil destes estudantes, destaca-se que a maioria é do sexo feminino (76,5\%). Possuem majoritariamente faixa etária entre 60 e 69 anos (4I,8\%), e entre 50 e 59 anos (26,4\%). Quanto ao estado civil, a maioria são casados $(45,4 \%)$ e $24,2 \%$ são divorciados. Quanto à ocupação, a maior parte são aposentados (79,4\%), e possuem renda familiar acima de quatro salários mínimos (53,5\%). Acerca da escolaridade, predominam as formações de nível superior completo $(39,4 \%)$ e Pós-Graduação (26,8\%). Em relação ao vínculo com o NETI, 38,6\% realizam atividades a menos de I ano, de I a 3 anos (30,9\%) e de 3 a 5 anos (15,9\%).

Olhar de professor, Ponta Grossa, v. 24, p. I-9, e-I58I4.028, 2021.

Disponível em <https://revistas2.uepg.br/index.php/olhardeprofessor> 
O "Programa Quarentena no NETI" foi idealizado pelos servidores do núcleo para promover a saúde e manter o vínculo com seus alunos no período de distanciamento social, em razão da pandemia pelo novo Coronavírus. Este Programa que teve seu início em março de 2020, e vem sendo desenvolvido remotamente neste período de distanciamento social, tem seu término previsto no retorno das atividades presenciais. A equipe do Núcleo que elaborou e implementou o Programa é composta pelos servidores: coordenadora do núcleo e Docente de Enfermagem, e os técnicos administrativos dos cargos de assistente social, técnico em assuntos educacionais, enfermeira, assistente em administração e chefe de divisão de apoio administrativo.

O desenvolvimento do Programa se dá por meio de duas postagens por semana, às segundasfeiras e quintas-feiras, pela manhã. Os materiais são escolhidos pela equipe de servidores, e enviado aos grupos de WhatsApp das atividades ofertadas no NETI. Para tal, foi criado um grupo no aplicativo com o professor/facilitador responsável, e os alunos matriculados na atividade. Os idosos inscritos nas atividades foram convidados a participar desse novo grupo, sendo respeitado o direito de recusa ou de não participação, bem como a sua saída do mesmo, sem nenhuma penalização ou constrangimento.

A operacionalização do Programa ocorre conforme os passos a seguir: I - equipe do NETI recebe sugestões de materiais; 2- equipe do NETI avalia os materiais; 3 - os conteúdos selecionados são discutidos na equipe e prevalecem os mais votados; 4- os conteúdos votados são postados por um membro da equipe, e é preparado um texto para ser enviado juntamente com a postagem; 5 todos da equipe avaliam o texto, aprovam ou sugerem alterações; 6- com o texto e o material aprovados, um membro da equipe encaminha aos grupos de WhatsApp dos alunos cadastrados nas atividades que realizam no NETI.

Para avaliar as postagens encaminhadas no Programa Quarentena no NETI foi selecionada, neste relato, análise de conteúdo do tipo temática, conforme Minayo (2014, p. 316), que consiste em "descobrir os núcleos de sentido que compõem uma comunicação, cuja presença ou frequência signifiquem alguma coisa para o objeto analítico visado". Envolve as etapas de: pré- análise (leitura flutuante, constituição do corpo e formulação/ reformulação de hipóteses e objetivos); a exploração do material (é classificatória e visa alcançar o núcleo de compreensão do texto, categorização, redução); e, o tratamento e interpretação (resultados brutos submetidos à estatísticas de porcentagem ou análise fatorial, para após fazer inferências ou interpretações) (MINAYO, 20I4).

A equipe do NETI considerou importante realizar uma avaliação processual do Programa. Para isto, elaborou um questionário on-line contendo quatro perguntas fechadas: I) Qual o seu curso em 2020/I? 2) Quão satisfeito você está em receber os conteúdos do Programa? 3) Avalie a 
Educação para idosos em tempo de pandemia no Núcleo de Estudos da Terceira Idade: relato de experiência contribuição do conteúdo enviado durante o período de distanciamento social. 4) Qual o seu formato preferido?

Uma vez finalizado o questionário, o mesmo foi encaminhado nos grupos de WhatsApp das atividades e solicitada a participação de todos os estudantes do Núcleo. O objetivo da avaliação foi verificar o vínculo e a participação dos estudantes idosos no Programa, e se o material enviado estava sendo interessante, útil e prático. Ao término do Programa, nova avaliação será preparada e encaminhada aos estudantes.

\section{Resultados e discussões}

Os resultados apresentados se referem ao período da primeira à décima postagem do Programa Quarentena no NETI. Nesses dez episódios do programa, foram veiculados um total de 30 materiais. A análise dos episódios demonstrou que treze $(43,33 \%)$ tinham relação com a arte (arquitetura, música, pintura, poesia); oito $(26,66 \%)$ com a ciência; cinco $(16,67 \%)$ tinham relação com a psicologia positiva (resiliência, felicidade, sucesso, transformação do caos em oportunidade, entre outros); dois $(6,67 \%)$ relacionados à história; e, dois $(6,67 \%)$ a conteúdos de meditação. Em I4 (46,66\%) desses tópicos mencionados, a temática se relaciona também à pandemia pelo COVID-19 (origem; distanciamento social; resiliência; música; mensagens de esperança e conforto; necessidade de mudança e descontração; jogo; ciência/reforma do pensar na pandemia; confecção de máscaras; desinfecção de ambientes e superfícies; bem-estar dos idosos; quarentena na arte e pintura).

A área de atuação e formação dos autores das postagens perpassa pelas áreas da saúde e humanas (biociências, medicina, enfermagem, psicologia), educadores (professores universitários, bibliotecários, filósofos, escritores, grupos de arte/TV), jornalistas, empresa de consultoria, websites e canais (google share, visita virtual, músicas, pintura, sociabilização).

Os resultados da avaliação pelos estudantes idosos explicitam a percepção deste quanto ao Programa. A consulta avaliativa, via questionário on-line (google forms), foi realizada no período de 30 de março de 2020 (primeira postagem) a 30 de abril 2020 (décima postagem) do Programa. Esta primeira avaliação de satisfação, concluída em 27 de abril de 2020, teve a participação de 29,3\% alunos idosos que responderam ao questionário.

A maioria $(96,7 \%)$ respondeu que está muito satisfeito e satisfeito com os conteúdos recebidos no Programa. O formato preferido dos estudantes idosos foram os vídeos (76, I\%), que estiveram presentes em $64,28 \%$ das postagens, seguidos da visita virtual em museus, jogos, livros, entrevistas, cartilhas, e-books, fotos e lives, sendo estes, cada um, numa porcentagem de 3,57\%. Ressalta-se aqui a preocupação da equipe em alternar diferentes formatos, de modo a destacar o

Olhar de professor, Ponta Grossa, v. 24, p. I-9, e-15814.028, 2021.

Disponível em <https://revistas2.uepg.br/index.php/olhardeprofessor> 
conteúdo para os idosos, com estímulos diversificados, possibilitando uma aprendizagem interessante, curiosa, descontraída e relaxante em alguns momentos.

Esse estudo vem ao encontro do que Argenta et al. (2020) argumentam sobre a importância de remodelar as ações individuais e coletivas durante o distanciamento social. Estas ações promovem benefício físico, emocional e social, e devem ser realizadas, respeitando a preferência do idoso, priorizando que sejam no ambiente domiciliar e adaptadas às suas condições de vida e saúde. As autoras reforçam positivamente as iniciativas de aulas on-line, com dicas, atividades interativas voltadas ao bem-estar físico e mental, promovendo a socialização e a interação tecnológica da população idosa.

O aumento de temas voltados para a terceira idade cada vez mais, tem sido uma prioridade, e revelou seu caráter emergencial durante a pandemia (SEABRA et al., 2019; HAMMERSCHMIDT; SANTANA, 2020). É essencial salientar que as ações devem contemplar temáticas que envolvam lazer, trocas de experiências populares, culinária, dentre outras (SEABRA et al., 2019).

A educação em saúde é entendida como um processo educativo de construção de conhecimentos, que visa à apropriação da temática pela população. Refere-se a um conjunto de práticas que contribuem para o aumento da autonomia individual e coletiva das pessoas, de modo a alcançar as necessidades dos indivíduos e das comunidades, melhorando a qualidade de vida e saúde da população (SEABRA et al., 2019).

\section{Considerações finais}

Considera-se que o projeto vem obtendo êxito com a atividade proposta. Especialmente, por manter o vínculo com os estudantes idosos durante o período de distanciamento social, por meio de estímulos cognitivos, enquanto a rotina educacional presencial não é retomada. Reafirmamos nossa prática educacional ancorada na educação não formal e permanente para idosos, como uma estratégia de manutenção do seu papel social, e com vistas a abrir o mundo do conhecimento, possibilitando o aprendizado ao longo de toda a vida. A educação e o envelhecimento configuram processos permanentes e dinâmicos na vida humana.

A busca por alternativas educacionais que visam contemplar a população idosa, nesse período de distanciamento social e para além, destacaram a necessidade de repensar as propostas de interação e cuidado, visando manter a autonomia e independência do público idoso, e suas particularidades enquanto sujeitos que aprendem e ensinam em interação com o meio, com os demais estudantes e com os professores. Este programa tem desencadeado um vasto processo de aprendizagem para a equipe do NETI. Reafirmarmos nossa defesa em respeito às peculiaridades do estudante idoso. Por fim, o Programa Quarentena no NETI tornou-se uma estratégia de articular a 
Educação para idosos em tempo de pandemia no Núcleo de Estudos da Terceira Idade: relato de experiência

educação não formal e permanente com idosos, com vistas à promoção da saúde física, mental e emocional dos estudantes idosos, e na manutenção de vínculos durante o distanciamento social ocasionado pela pandemia de COVID-19.

\section{Referências}

ARGENTA, C. et al. Distanciamento social do idoso saudável durante a pandemia COVID-19: possibilidades e desafios. In: SANTANA, R. F. et al. Enfermagem Gerontológica do cuidado do idoso em tempo da COVID-19. Disponível em: http://www.abennacional.org.br/site/wpcontent/uploads/2020/05/E-BOOK-GERONTO.pdf. Acesso em: 21 maio 2020.

BRASIL. Lei $n^{\circ}$ 8.842, de 04 de janeiro de 1994. Dispõe sobre a política nacional do idoso, cria o Conselho Nacional do Idoso e dá outras providências. Diário Oficial da União: Brasília, DF., 1994. Disponível em: http://www.planalto.gov.br/ccivil_03/leis//8842.htm. Acesso em: 25 maio 2020.

BRASIL. Lei $n^{\circ} 10.741$, de 01 de outubro de 2003. Dispõe sobre o Estatuto do Idoso e dá outras providências. Diário Oficial da União: Brasília, DF., 2003. Disponível em: http://www.planalto.gov.br/ccivil_03/leis/2003//I0.74I.htm. Acesso em: 25 maio 2020.

BRASIL. Lei $n^{\circ}$ 13.979, de 06 de fevereiro de 2020. Dispõe sobre as medidas para enfrentamento da emergência de saúde pública de importância internacional decorrente do coronavírus responsável pelo surto de 2019. Diário Oficial da União: Brasília, DF., edição 27, seção I, 2020a. Disponível em: http://www.in.gov.br/en/web/dou/-/lei-n-13.979-de-6-de-fevereiro-de-2020-242078735. Acesso em: 25 maio 2020.

BRASIL. Portaria n. 454, de 20 de março de 2020. Declara, em todo o território nacional, o estado de transmissão comunitária do coronavírus (covid-19). Diário Oficial da União: Brasília, DF., edição 55, seção I, 2020b. Disponível em: http://www.in.gov.br/en/web/dou/-/portaria-n-454-de-20-demarco-de-2020-24909I587. Acesso em: 25 maio 2020.

CACHIONI, M.; ORDONEZ, T. N. Universidade da Terceira Idade. In: FREITAS, E. V.; PY, L. Tratado de geriatria e gerontologia. 4. ed. Rio de Janeiro: Guanabara Koogan, 2017.

HAMMERSCHMIDT, K. S. A.; SANTANA, R. F. Saúde do idoso em tempos de pandemia COVID-19. Revista Cogitare Enfermagem, Curitiba/PR, v. 25, 2020. Disponível em: https://revistas.ufpr.br/cogitare/article/view/72849/pdf. Acesso em: 21 maio 2020.

LIMA, K. C. et al. A pessoa idosa domiciliada sob distanciamento social: possibilidades de enfrentamento à covid-19. Revista Brasileira de Geriatria e Gerontologia, Maracanã/RJ, v. 23, n. 2, 2020. Disponível em: https://www.rbgg.com.br/edicoes/v23n2/RBGG\%20v23n2\%20PORT_Editorial.pdf. Acesso em: 25 maio 2020.

MINAYO, M. C. de S. O desafio do conhecimento: pesquisa qualitativa em saúde. 14. ed. São Paulo: Hucitec, 2014.

SEABRA, C. A. M. et al. Educação em saúde como estratégia para promoção da saúde dos idosos: uma revisão integrativa. Revista Brasileira de Geriatria e Gerontologia, Maracanã/RJ, v. 22, n.

Olhar de professor, Ponta Grossa, v. 24, p. I-9, e-I58|4.028, 202 I.

Disponível em <https://revistas2.uepg.br/index.php/olhardeprofessor> 
Michele Medeiros e Maria Fernanda Baeta Neves Alonso da Costa e Guilherme Henrique Koerich

4, 2019. Disponivel em: https://www.scielo.br/scielo.php?pid=SI809982320 I900040030I\&script=sci_arttext\&tlng=pt. Acesso em: 25 maio 2020.

Recebido em: 06 de junho de 2020.

Versão corrigida recebida em: 12 de agosto de 2020.

Aceito em: 12 de agosto de 2020.

Publicado online em: 01 de abril de 2021 .

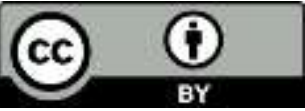

